\title{
СОСТАВ, СТРУКТУРА И ЭЛЕКТРОННЫЕ СВОЙСТВА СdТе С НАНОРАЗМЕРНЫМИ ФАЗАМИ, СОЗДАННЫМИ В ПРИПОВЕРХНОСТНОМ СЛОЕ ИМПЛАНТАЦИЕЙ ИОНОВ Ва
}

\author{
Ё.С. Эргашов, Б.Е. Умирзаков \\ Ташкентский государственный технический университет, 100095 Ташкент, Узбекистан \\ yergashev@mail.ru \\ (Получена 29.01.2018)
}

\begin{abstract}
$\mathrm{Ba}^{+}$ионларини $E_{0}=15$ ва 30 кэВ энергияларда имплантация килиш усулидан фойдаланган хєолда уч қุатламли $\mathrm{CdTe} / \mathrm{Cd}_{0.5} \mathrm{Ba}_{0.5} \mathrm{Te} / \mathrm{CdTe}$ тизим олиниб, ион имплантация қุилишнинг оптимал режимлари ва қиздирилишдаги шаклланиши аникпланди. Ион бомбардимон жараёнида $\mathrm{CdTe}$ сирт қ্атламларида ионларнинг дозасига боғлиқ равишда сирт тартибсизланиши ва сирт қатламларининг бойитилиши куурсатилган. Ионлар билан легирланган қатламлар таркиби ва электрон тузилиши оптимал температурада қุиздирилгандан сўнг ўрганилган.

С использованием метода имплантации ионов $\mathrm{Ba}^{+}$с $E_{0}=15$ и 30 кэВ получена трехслойная система $\mathrm{CdTe} / \mathrm{Cd}_{0.5} \mathrm{Ba}_{0.5} \mathrm{Te} / \mathrm{CdTe}$ и определены оптимальные режимы ионной имплантации и отжига их формирования. Показано, что в процессе ионной бомбардировки приповерхностного слоя в зависимости от дозы ионов СdTе сильно разупорядочивается и различные слои обогащаются. Изучены состав и электронная структура ионно-легированных слоев до и после прогрева при оптимальной температуре.
\end{abstract}

With using the method of $\mathrm{Ba}^{+}$ion's implantation with $E_{0}=15$ and $30 \mathrm{keV}$ the triplex system $\mathrm{CdTe} / \mathrm{Cd}_{0,5} \mathrm{Ba}_{0,5} \mathrm{Te} / \mathrm{CdTe}$ has been received. The optimum modes of ionic implantation and annealing of their formation are defined. It is shown that subsurface layers of CdTe are strongly disordered with increasing dose of ions up to $10^{15} \mathrm{~cm}^{-2}$. The structure and electronic properties of ion-implantated layers are investigated before and after annealing.

\section{I. ВВЕДЕНИЕ}

В последние годы для получения наноразмерных структур на различной глубине полупроводников широко используются методы ионной имплантации, лазерной обработки и СВЧ-облучения [1-5]. Эти структуры имеют большие перспективы при создании новых приборов микро-, нано- и оптоэлектроники. В частности, гетероструктуры на основе СdТе могут быть использованы в качестве эффективных детекторов излучения в широком частотном диапазоне, включая солнечный $[2,6,7]$.

Нами ранее методом низкоэнергетической $\left(E_{0}=0.5-2\right.$ кэВ) ионной бомбардировки на поверхности пленки $\mathrm{CdTe} / \mathrm{Mo}(111)$ получены наноразмерные фазы $\mathrm{Cd}$, Те и Ва и изучено их влияние на морфологию и электронные свойства поверхности пленки [8-9]. Показано, что при имплантации ионов $\mathrm{Ba}^{+}$дозой $D \leq 5 \times 10^{15} \mathrm{~cm}^{-2}$ поверхность обогащается атомами Ва и Те, а при $D>5 \times 10^{15} \mathrm{~cm}^{-2}$ атомами Ва и $\mathrm{Cd}$. Эти изменения происходят до дозы $D=6 \times 10^{16} \mathrm{~cm}^{-2}$. При этом поверхностные концентрации $\mathrm{Ba}, \mathrm{Te}$ и $\mathrm{Cd}$ соответственно составляют $40-45,45-50$ и 10-15 ат.\%. Постимплантационный отжиг этого образца приводит к формированию 
наноэпитаксиальной пленки типа $\mathrm{Cd}_{0.5} \mathrm{Ba}_{0.5} \mathrm{Te}$ толщиной 20-30 $\AA$. Ширина запрещенной зоны $E_{g}$ трехкомпонентной пленки $\mathrm{Cd}_{0.5} \mathrm{Ba}_{0.5} \mathrm{Te}$ в зависимости от его толщины меняется в пределах 1.6-1.8 эВ [9]. Что касается получения наноразмерных фаз в приповерхностном слое, то такие исследования проведены только для монокристаллов Si [10]. Данная работа посвящена получению наноразмерных структур типа $\mathrm{CdBaTe}$ в приповерхностном слое $\mathrm{CdTe}$ имплантацией ионов $\mathrm{Ba}^{+}$в сочетании с отжигом и изучению их состава и электронных свойств.

\section{II. МЕТОДИКА ЭКСПЕРИМЕНТА}

Объектами исследования являются монокристаллические образцы $\mathrm{CdTe}(111)$ толщиной $\sim 0.6$ мм. Термическую очистку и ионную имплантацию образцов проводили при вакууме не хуже $10^{-6}$ Па. Исследования проводили с использованием методов оже-электронной спектроскопии (ОЭС), дифракции быстрых электронов (ДБЭ), также снимали зависимость интенсивности $I$ проходящего через образец света от его энергии при вакууме $\sim 10^{-7}$ Па. Профили распределения атомов по глубине определяли методом ОЭС в сочетании с послойным травлением ионами $\mathrm{Ar}^{+}$с $E_{0}=2-3$ кэВ под углом 5-10 поверхности образца.

\section{III. ЭКСПЕРИМЕНТАЛЬНЫЕ РЕЗУЛЬТАТЫ}

Для получения наноразмерных фаз и нанослоев в приповерхностной области $\mathrm{CdTe}$ имплантацию ионов $\mathrm{Ba}^{+}$проводили с энергией $E_{0} \geq 10$ кэВ [10]. На рис. 1 приведены зависимости поверхностной концентрации атомов $\mathrm{Cd}$, Те и Ва от дозы ионов для $\mathrm{CdTe}(111)$, имплантированного ионами $\mathrm{Ba}^{+}$с $E_{0}=15$ кэВ. Из рис. 1 видно, что сначала с ростом дозы ионов до $D=10^{14} \mathrm{~cm}^{-2}$ концентрация Сd увеличивается на $10-15$ ат.\%, в интервале $D=10^{14}-10^{16} \mathrm{~cm}^{-2}$ резко уменьшается до $\sim 8-10$ ат.\%, затем при $D \geq 5 \times 10^{16} \mathrm{~cm}^{-2}$ заметно не меняется. Поверхностная концентрация Те сначала при $D \approx(2-3) \times 10^{14} \mathrm{~cm}^{-2}$ проходит через минимум ( 40 ат.\%), затем при $D \approx 5 \times 10^{16}$ $\mathrm{cm}^{-2}$ через максимум ( 85-90 ат.\%).

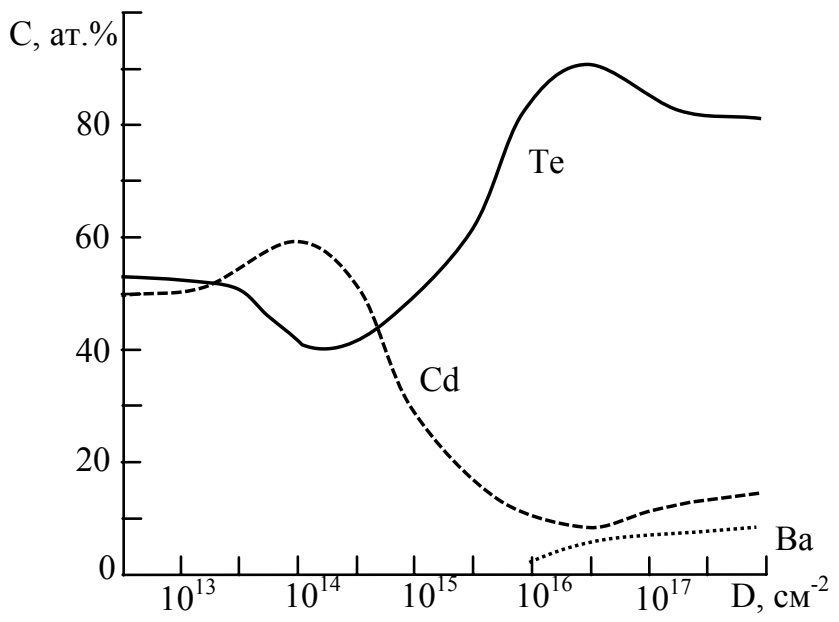

Рис. 1. Зависимость поверхностной концентрации атомов $\mathrm{Cd}$, Те и Ва от дозы облучения для $\mathrm{CdTe}$, имплантированного ионами $\mathrm{Ba}$ с $E_{0}=15$ кэВ. 
Начиная с $D=10^{16} \mathrm{~cm}^{-2}$ на поверхности появляются атомы Ва и при $D \approx 10^{17} \mathrm{~cm}^{-2}$ концентрация $C_{\mathrm{Ba}}$ составляет 5-6 ат.\%. При $D \approx 10^{17} \mathrm{~cm}^{-2}$ поверхностные концентрации Те, $\mathrm{Cd}$ и Ва устанавливаются соответственно на уровне $82-84$ ат.\%, 10-12 ат.\%, 6-8 ат.\%. Дальнейшее увеличение $D$ не приводит к заметному изменению состава поверхности. Поверхностные слои $\mathrm{CdTe}$, начиная с дозы ионов $d \sim 10^{15} \mathrm{~cm}^{-2}$, полностью разупорядочиваются.

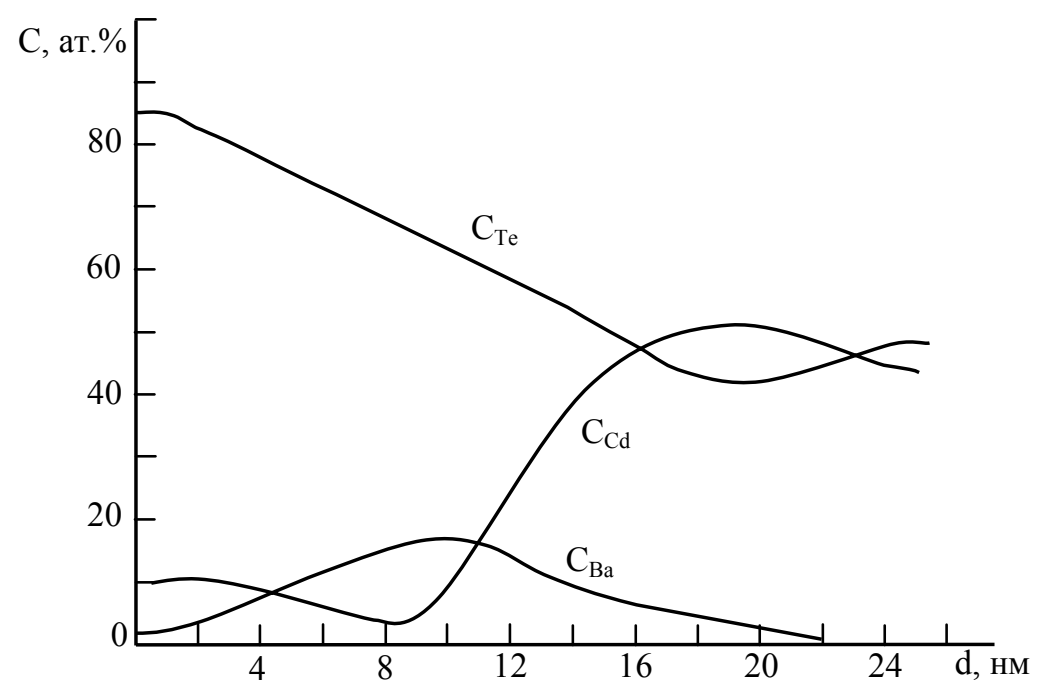

Рис. 2. Концентрационные профили распределения атомов $\mathrm{Cd}$, Те и Ва по глубине $\mathrm{CdTe}$, имплантированного ионами Ва с $E_{0}=15$ кэВ при дозе $D=10^{17} \mathrm{~cm}^{-2}$.

На рис. 2 приведены концентрационные профили распределения атомов $\mathrm{Cd}, \mathrm{Te}$ и $\mathrm{Ba}$ по глубине для СdTe, имплантированного ионами $\mathrm{Ba}^{+}$с $E_{0}=15$ кэВ при $D=D_{H}=10^{17} \mathrm{~cm}^{-2}\left(D_{u}-\right.$ доза насыщения). Из рис. 2 видно, что до глубины $d \approx 2 \mathrm{Hм}$ концентрации всех элементов заметно не меняются, затем с ростом $d$ их концентрации немонотонно изменяются: $C_{\mathrm{Te}}(d)$ проходит через минимум при $d \approx 18-20 \mathrm{нм}, C_{\mathrm{Ba}}-$ через максимум при $d \approx 10 \mathrm{Hм}$, а $C_{\mathrm{Cd}}$ проходит сначала через минимум при $d \approx 8$ нм, а затем через максимум при $d \approx 18-20$ нм. При $d \approx 24$ нм концентрация Ва уменьшается до нуля, а концентрации Те и Сd соответственно составляют 50-52 ат.\% и 48-50 ат.\%. Анализ результатов ОЭС показал, что на различных глубинах ионно-легированного слоя сохраняется высокая концентрация Те. По-видимому, при ионной бомбардировке разложение СdTe сопровождается преимущественной диффузией атомов $\mathrm{Cd}$ и Те к поверхности и внедрением Ва в приповерхностном слое. Основная часть атомов Сd испаряется (распыляется) с поверхностных слоев, а атомы Те - испаряются незначительно, так как они находятся в виде $\mathrm{Te}_{2}$. Следовательно, поверхностные слои с толщиной 2-3 нм обогащаются теллуром. В этих слоях также содержится некоторое количество $\mathrm{Cd}$ (10-12 ат.\%), и они образуют соединения типа $\mathrm{Cd}+\mathrm{Te}$. В интервале $d \approx 2-12$ нм преимущественно образуются соединения типа Ва+Те, в интервале $d \approx 12-20$ нм $\mathrm{Ba}+\mathrm{Cd}+\mathrm{Te}$, а при $d \geq 20-22$ нм - CdTe. В ионно-легированном слое в зависимости от глубины также содержатся несвязанные атомы $\mathrm{Cd}$, Те и Ва. 
На рис. 3 приведены изменения интенсивности $I$ света при прохождении через нелегированный и легированный ионами $\mathrm{Ba}^{+}\left(E_{0}=15\right.$ кэВ, $\left.D=10^{17} \mathrm{~cm}^{-2}\right)$ образцы $\mathrm{CdTe}$, в интервале $h v \approx 0.2-1.7$ эВ. В случае чистого СdTе зависимость $I(h v)$ до $h v \approx 1.35$ эВ существенно не меняется, а в интервале $1.35-1.45$ эВ резко уменьшается. Экстраполяция этой кривой к оси $h v$ дает оценочные значения ширины запрещенной зоны, которая примерно равна 1.48 эВ. В случае ионноимплантированного СdTе при $h v \approx 0.2$ эВ значение $I$ составляет $0.7 \mathrm{~B}$, интервале $h v=0.25-0.35$ эВ уменьшается до 0.25 , затем монотонно уменьшается и при $h v \approx 1.4$ эВ равняется нулю.

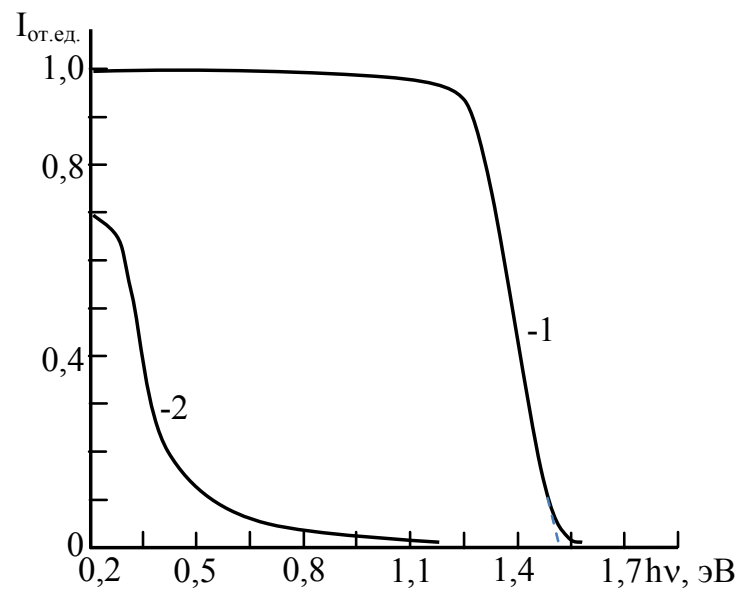

Рис. 3. Зависимость интенсивности проходящего через образец света от энергии фотонов: 1 - для нелегированного $\mathrm{CdTe}, 2$ - для СdTe, имплантированного ионами $\mathrm{Ba}^{+}$с $E_{0}=15$ кэВ и дозой $D=10^{17} \mathrm{~cm}^{-2}$.

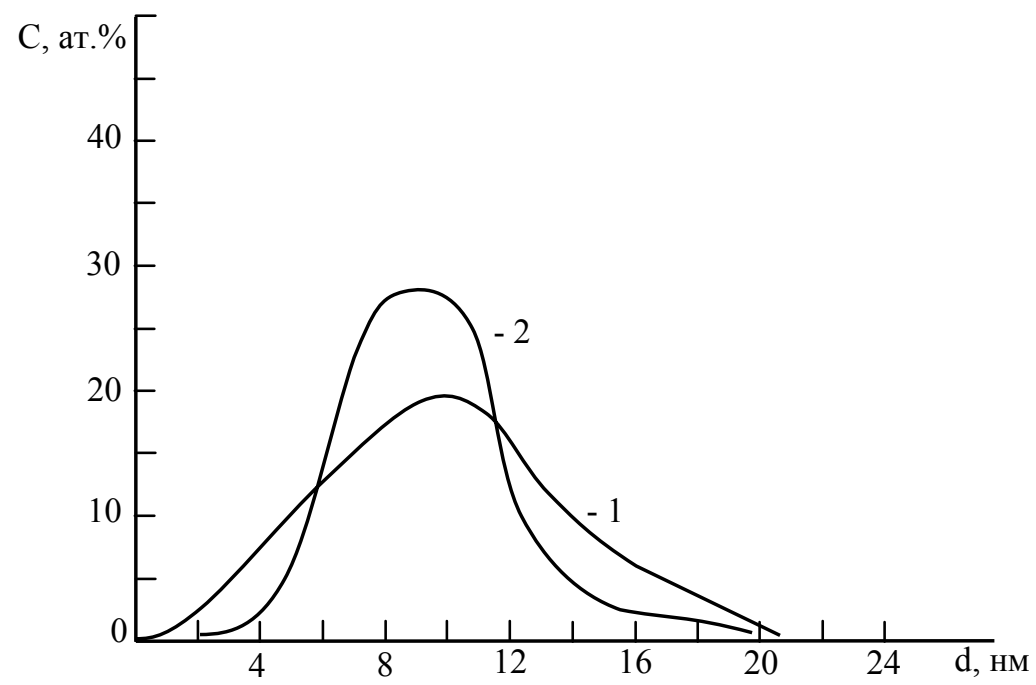

Рис. 4. Концентрационные профили распределения атомов Ва по глубине для СdTe, имплантированного ионами $\mathrm{Ba}^{+}$с $E_{0}=15$ кэВ и дозой $D=10^{17} \mathrm{~cm}^{-2}: 1$ - до прогрева; 2 - после прогрева при $T=1000$ К. 
Постимплантационный отжиг в зависимости от температуры приводит к перераспределению атомов $\mathrm{Ba}, \mathrm{Cd}$ и $\mathrm{Te}$ в ионно-легированном слое и кристаллизации разупорядоченных слоев. Отжиг при каждой температуре проводили в течение 30 мин. Полная кристаллизация наблюдается при $T=1000 \mathrm{~K}$. При этом концентрация Ва в максимуме увеличивается до 25-28 ат.\%, общая концентрация $\mathrm{Ba}$ (площадь под кривой $C_{\mathrm{Ba}}(d)$ ) немного уменьшается и положение максимума смешается к поверхности (рис. 4). При этом на глубине $d=8-9$ нм формируется слой $\mathrm{Cd}_{0.5} \mathrm{Ba}_{0.5}$ Те толщиной $\sim 6-8$ нм. Ссылаясь на результаты работы [10], можно полагать, что $E_{g}$ этого слоя составляет $\sim 1.7-1.8$ эВ. В результате образуется трехслойная система $\mathrm{CdTe} / \mathrm{Cd}_{0.5} \mathrm{Ba}_{0.5} \mathrm{Te} / \mathrm{CdTe}$. Между этими слоями содержится переходный слой типа $\mathrm{Cd}_{1-x} \mathrm{Ba}_{x} \mathrm{Te}(x=0-0.5)$.

Аналогичные результаты получены при увеличении энергии до $\sim 30$ кэВ. В таблице приведены значения $d_{\mathrm{m}}$ (глубина, которая соответствует максимуму распределения $\mathrm{Ba}), C_{\mathrm{m}}$ (концентрация $\mathrm{Ba}$ в максимуме), $\Delta d$ (полуширина кривой распределения - толщина слоя $\mathrm{Cd}_{0.5} \mathrm{Ba}_{0.5} \mathrm{Te}$ ), полученные для $\mathrm{CdTe}$, имплантированного ионами $\mathrm{Ba}^{+}$с энергиями 15 и 30 кэВ при $D=D_{\text {н }}$ до и после прогрева (в случае $E_{0}=30$ кэВ доза насыщения $\sim 3 \times 10^{17} \mathrm{~cm}^{-2}, T_{\text {опт }}=1100 \mathrm{~K}$ ).

Таблица. Значения $d_{\mathrm{m}}, C_{\mathrm{m}}, \Delta d$ и $x$ для СdTe, имплантированного ионами $\mathrm{Ba}^{+}$.

\begin{tabular}{l|l|c|c}
\hline \multirow{2}{*}{ Параметр } & \multirow{2}{*}{ Прогрев } & \multicolumn{2}{|c}{$E_{0}$, кэВ } \\
\cline { 3 - 4 } & & 15 & 30 \\
\hline$d_{\mathrm{m}}$, нм & до прогрева & $9-10$ & $16-18$ \\
\multirow{2}{*}{$C_{\mathrm{m}}$, ат.\% } & после & $8-9$ & $16-18$ \\
& до & $20-22$ & $13-15$ \\
\multirow{2}{*}{$\Delta, \mathrm{Hм}$} & после & $26-28$ & $18-20$ \\
& до & 12 & 20 \\
& после & $7-8$ & $9-10$ \\
\hline
\end{tabular}

Из таблицы видно, что с ростом энергии ионов максимум распределения смещается в сторону больших энергий, полуширины кривой распределения увеличиваются, а концентрация бария в максимуме уменьшилась. Для $E_{0}=30$ кэВ значение $d_{\mathrm{m}}$ до и после прогрева не отличаются друг от друга. Это объясняется тем,

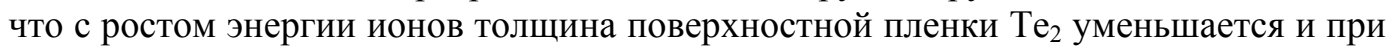
$E_{0}=30$ кэВ составляет всего $\sim 0.5$ нм. После прогрева концентрация Ва в вакууме увеличивается почти в 2 раза и образуется слой $\mathrm{Cd}_{0.6} \mathrm{Ba}_{0.4}$ Те толщиной $\sim 20$ нм.

\section{IV. ОБСУЖДЕНИЕ И АНАЛИЗ ПОЛУЧЕННЫХ РЕЗУЛЬТАТОВ}

В процессе ионной имплантации бинарных материалов происходит разложение их на составляющие, внедрение легирующей примеси и разупорядочение приповерхностных слоев. Наибольшее изменение наблюдается на глубине материала, соответствующей максимуму распределения имплантированных ионов. В случае $\mathrm{CdTe}$, имплантированного ионами $\mathrm{Ba}^{+}$с $E_{0}=15$ кэВ максимум распределения Ва наблюдается на глубине 8-10 нм. При низких дозах ионов $\left(D \leq 10^{15} \mathrm{~cm}^{-2}\right)$ эти процессы происходят на отдельных участках $\mathrm{CdTe}[8,9]$. C ростом дозы ионов размеры этих участков увеличиваются и, начиная с $D=10^{16} \mathrm{~cm}^{-2}$, происходит перекрывание их границ, следовательно формируется сплошной ионно- 
имплантированный слой. При низких дозах ионов после разложения часть атомов $\mathrm{Te}$ и $\mathrm{Cd}$ вновь образует соединение $\mathrm{Cd}+\mathrm{Te}$, а другая часть атомов Те образует соединения типа $\mathrm{Te}_{2}$, а Сd диффундирует к поверхности. При $D=10^{15} \mathrm{~cm}^{-2}$, наряду с диффузией атомов $\mathrm{Cd}$ к поверхности, происходит их частичное распыление. С ростом дозы ионов распыление $C_{\mathrm{Cd}}$ увеличивается и поверхностная область толщиной $d=2-3$ нм обогащается молекулами $\mathrm{Te}_{2}$. При $D \geq 10^{16} \mathrm{~cm}^{-2} C_{\mathrm{Cd}}$ практически не меняется. Однако вследствие появления и увеличения концентрации Ва на поверхности $C_{\mathrm{Te}}$ незначительно уменьшается. Начиная с дозы ионов $D=(8-10) \times 10^{16} \mathrm{~cm}^{-2}$ поверхность практически не меняется, т.е. эта доза является дозой насыщения.

При дозе насыщения концентрация Ва в области максимума распределения увеличивается до 18-20 атомных процентов, что приводит к уменьшению в этих слоях концентрации атомов $\mathrm{Cd}$ и Те (рис. 2). При $d=18-20$ нм $C_{\mathrm{Cd}}(d)$ проходит через максимум, $C_{\mathrm{Te}}(d)$ - через минимум. Так как на этой глубине $C_{\mathrm{Ba}}$ приближается к нулю, то можно полагать, что в процессе ионной бомбардировки $\mathrm{Cd}$ диффундирует не только на поверхность, но и в глубь мишени.

По всему ионно-легированному слою и вблизи него часть атомов Те образует нестехиометрические соединения с атомами $\mathrm{Cd}$ и $\mathrm{Ba}$. В интервале $d=0-2$ нм преимущественно образуются соединения типа $\mathrm{Cd}+\mathrm{Te}$, в интервале $d=2-10 \mathrm{Hм}-$ $\mathrm{Ba}+\mathrm{Te}$, в интервале $d=10-16$ нм - Ва+Те и $\mathrm{Ba}+\mathrm{Cd}+\mathrm{Te}$, при $d \geq 16$ нм $-\mathrm{Cd}+\mathrm{Te}$. Эти соединения обладают свойствами полупроводника, поэтому через ионнолегированный образец проходит свет с энергией $h v \leq 1.3-1.4$ эВ (рис. 3). Резкое уменьшение интенсивности проходящего света начинается с $h v=0.3-0.35$ эВ, что соответствует ширине запрещенной зоны пленки Те. На поверхности содержится также некоторое количество соединений типа $\mathrm{Cd}+\mathrm{Te}$, а в приповерхностном слое $\mathrm{Ba}+\mathrm{Te}, \mathrm{Ba}+\mathrm{Cd}+\mathrm{Te}$. Ширины запрещенных зон этих соединений, по-видимому, больше, чем $E_{g}$ пленки $\mathrm{Te}_{2}$, следовательно, свет проходит через этот образец до $h v=1.2-1.3$ эВ. Смещение положения максимума кривой $C_{\mathrm{Ba}}(d)$ на $1-2$ нм после прогрева при $T=1000$ К, по-видимому, связано с некоторым испарением $\mathrm{Te}_{2}$ и $\mathrm{Ba} \mathrm{c}$ поверхностных слоев (рис. 4).

\section{V. ЗАКЛЮЧЕНИЕ}

Таким образом, впервые изучено изменение состава, структуры и электронных свойств поверхности и приповерхностных слоев СdTе при имплантации ионов $\mathrm{Ba}^{+} \mathrm{c}$ $E_{0}>10$ кэВ. Показано, что ионно-легированные слои имеют сложный, изменяющийся по глубине и составу характер и обладают свойствами узкозонного полупроводника, ширина запрещенной зоны которого изменяется в пределах 0.3-1.2 эВ. После прогрева при $T=1000 \mathrm{~K} \mathrm{CdTe}$, имплантированного дозой насыщения, в приповерхностном слое образуются соединения типа $\mathrm{Cd}_{0.5} \mathrm{Ba}_{0.5} \mathrm{Te}$ и формируется трехслойная система $\mathrm{CdTe} / \mathrm{Cd}_{0.5} \mathrm{Ba}_{0.5} \mathrm{Te} / \mathrm{CdTe}$. Глубина формирования трехкомпонентного соединения и его ширина зависят от энергии ионов: при $E_{0}=15$ кэВ $d_{\mathrm{m}}=9-10$ нм, $\Delta d=7-8$ нм; при $E_{0}=30$ кэВ $d_{\mathrm{m}}=16-18$ нм, $\Delta d=9-10$ нм.

\section{ЛИТЕРАТУРА}

1. В.Н. Бабенцов, А. Байдуллаева, А.И. Власенко и др., Физика и техника полупроводников 27, №10, 1618 (1993). 
2. В.П. Махний, Физика и техника полупроводников 39, №7, 826 (2005).

3. M.K. Herndon, A. Gupta, V.I. Kaydanov, R.T. Collins, Appl. Phys. Lett. 75, 3503 (1999).

4. Y.S. Ergashov, D.A. Tashmukhamedova, E. Rabbimov, Journal of Surface Investigation. X-ray, Synchrotron and Neutron Techniques (Russia) 9, №2, 350 (2015).

5. D.A. Tashmukhamedova, M.K. Ruzibaeva, F.G. Djurabekova, S.B. Danaev, Nuclear Instruments and Methods in Physics Research B 326, 322 (2014).

6. C.H. Lee, S.W. Park, Jaesun Lee, Y.M. Moon, et al., J. Electron. Mater. 27, № 6,. 668 (1998).

7. А. Фаренбрух, Р. Бьюб. Солнечные элементы: теория и эксперимент (Москва, Мир, 1987).

8. Y.S. Ergashov, D.A. Tashmukhamedova, F.G. Djurabekova, B.E. Umirzakov, Bulletin of the Russian Academy of Sciences. Physics 80, № 2, 138 (2016).

9. 3.Э. Мухтаров, З.А. Исаханов, Б.Е. Умирзаков, Т. Кодиров, Ё.С. Эргашев, Журнал технической физики 85, № 12, 146 (2015).

10. Y.S. Ergashov, D.A. Tashmukhamedova, B.E. Umirzakov, Journal of Surface Investigation: X-ray, Synchrotron and Neutron Techniques 11, №. 2, 480 (2017). 